\title{
Ischemic retinal vasculitis in an 18-year-old man with chickenpox infection
}

This article was published in the following Dove Press journal:

Clinical Ophthalmology

24 February 2014

Number of times this article has been viewed

\section{Anuchit Poonyathalang \\ Somsiri Sukavatcharin \\ Tharikarn Sujirakul \\ Department of Ophthalmology, Ramathibodi Hospital, Mahidol University, Bangkok, Thailand}

Correspondence: Tharikarn Sujirakul Retina Service, Ophthalmology Department, Ramathibodi Hospital, 270 Rama VI Road, Bangkok 10400, Thailand

Tel +66220 I I526

Fax +66 23547280

Email tsujirakul@gmail.com
Abstract: Ocular involvement after primary infection with varicella zoster virus is very rare. We report a case of a healthy 18 -year-old man who presented with unilateral ischemic retinal vasculitis 10 days after the onset of chickenpox. He developed acute severe visual loss and a relative afferent pupillary defect in his right eye. Fundus imaging, optical coherence tomography, fundus fluorescence angiography, and electrophysiologic studies confirmed the diagnosis of retinal vasculitis, which led to generalized retinal ischemia. Although aggressive treatment with systemic steroids and antiviral drugs was administered, a poor visual outcome still resulted.

Keywords: ischemic retinal vasculitis, chickenpox, varicella zoster virus

\section{Introduction}

Ocular and orbital involvement of varicella zoster virus (VZV) had been reported after reactivation of the virus, most commonly associated with herpes zoster ophthalmicus. ${ }^{1,2}$ Ocular involvement after primary VZV infection or chickenpox is rare, usually occurring in children and young adolescents with acute retinal necrosis or optic neuritis. ${ }^{3-7}$ There are very few case reports of isolated ischemic retinal vasculitis associated with chickenpox, ${ }^{8}$ and those that do exist usually have limited fundus photographs or other investigations to support the diagnosis. Herein we present the case of ischemic retinal vasculitis associated with chickenpox and complete investigations to confirm the diagnosis.

\section{Case report}

A healthy 18-year-old man presented with a 2 -week history of chickenpox, and was treated with oral acyclovir for 5 days. Ten days after onset of the cutaneous vesicular eruptions, he experienced blurring of vision in his right eye that descended to the level of hand motion (HM) in 6 hours. At presentation, 4 days after blurred vision, visual acuity in his right eye was hand movement. Examination of the anterior segments was unremarkable except for an obvious relative afferent pupillary defect. His extraocular muscle examination was normal. Fundus examinations revealed an edematous disc, retinal whitening and edema along the posterior pole, and the presence of a cherry red spot; no retinal infiltration or vitreous opacity was observed (Figure 1A). His left eye was normal with 20/20 vision. Optical coherence tomography showed increased thickness and hyperreflectivity in the inner retina layer, consistent with inner retina infarction. The early phase of fundus fluorescein angiography demonstrated delayed filling of the optic disc with minimal leakage from the small retinal arteriole, which 


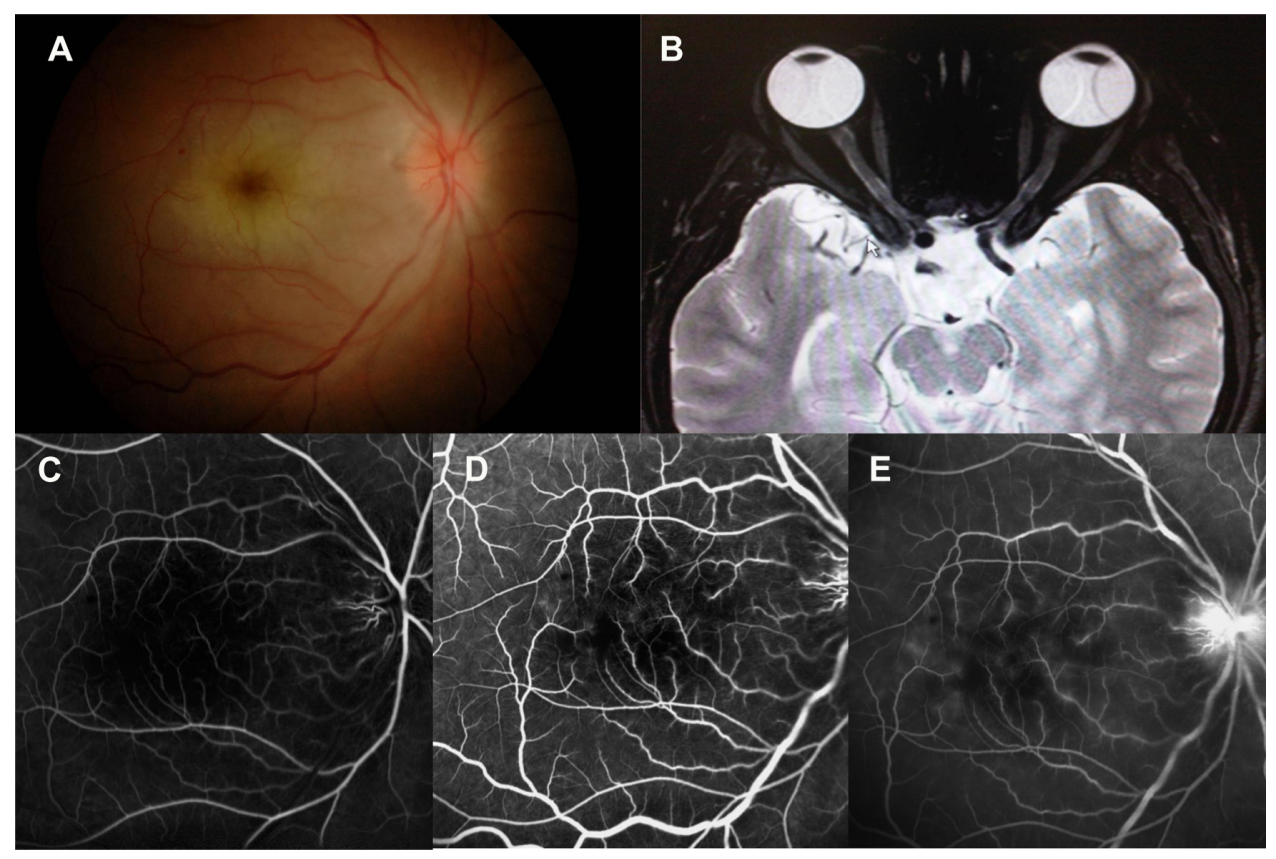

Figure I (A) Fundus photograph at presentation showing optic disc edema, whitening and edema of the posterior pole, and a cherry red spot. (B) Increased signal in T2-weighted magnetic resonance imaging and enhancing with contrast in right optic nerve. (C-E) Fundus fluorescein angiogram showing capillary dropout area, minimal vascular and disc leakage.

A

Right eye
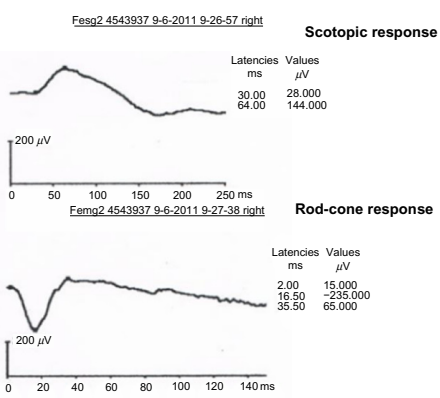

Cone response

Fedwug 24543937 9.6-2011 9-05-18 righ

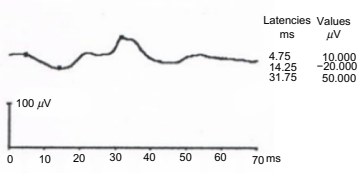

$30 \mathrm{HZ}$ flicker respons

Fedwuge 24543937 9-6-20119-05.57 right

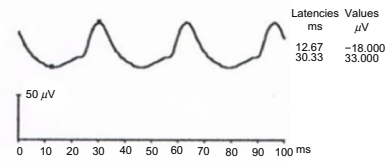

Feog2 4543937 9-6-2011 9-29.58 right

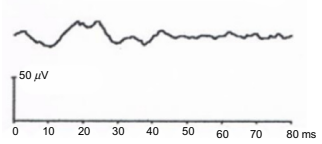

Left eye
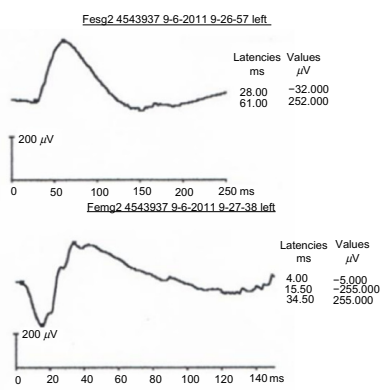

Fedwug 2 4543937 9-6-2011 9-05-18 left

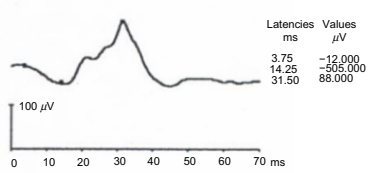

edwwo2 2543937 9.6-2011 9.05.57 lett.
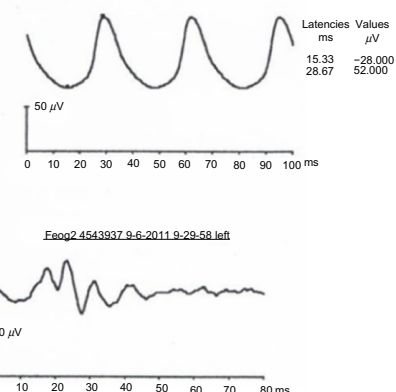

B

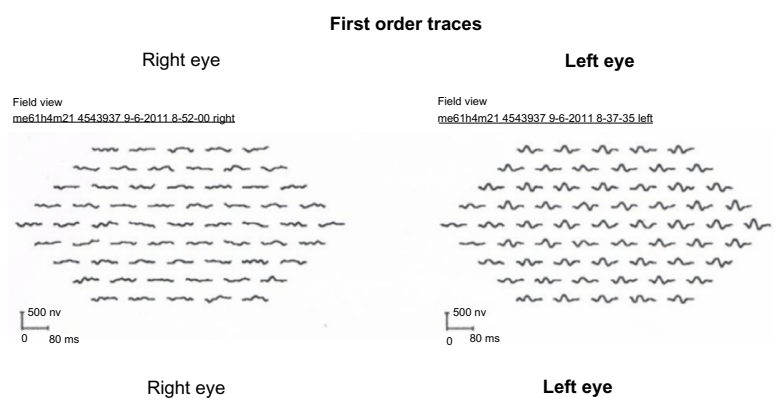

Field view
Me661h4m21 4543937 8.42011 14-05-40 right

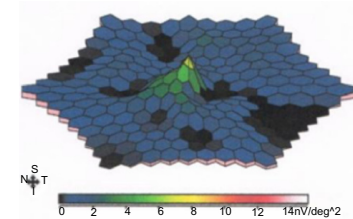

Field view
Me61h4m21 4543937 8-4-2011 14-05-40 le

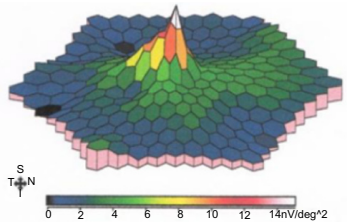

C

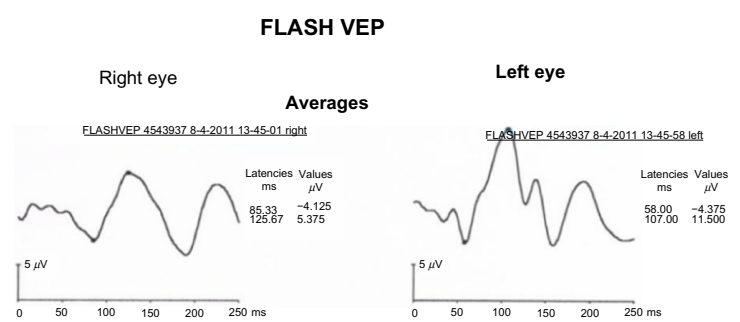

Figure 2 (A) Full field electroretinogram (ERG) showing reduction of oscillatory potentials (OP) wave and b-wave amplitude in rod-specific, cone-specific, and maximal electroretinogram in the right eye. (B) Diminished waveform of multifocal electroretinogram in central area of the right eye. (C) Flash visual evoked potential (VEP) showing both amplitude reduction and delayed implicit time in the right eye. 
was more prominent in the macular and optic disc regions. Minimal capillary dropout in the macular area was also noted. Staining of small vessels was observed in the late phase of the angiogram (Figure $1 \mathrm{C}-\mathrm{E}$ ). A multifocal electroretinogram (ERG) showed diminished waveform in the entire macular area (Figure 2B). A full field ERG showed decreased $b$-wave amplitude of both rod and cone response and oscillatory potential wave. Electronegative ERG pattern was evidenced in maximal combined ERG that represented a generalized ischemic process, which involved mainly the inner retina layer (Figure 2A). The patient demonstrated decreased amplitude and increased latency in flash visual evoked potential (VEP), which is consistent with generalized involvement of the entire retina, not limited only to the posterior pole (Figure 2C).

Minimal increased signal in T2-weighted magnetic resonance imaging and enhancing with contrast limited to the anterior part of the optic nerve could represent an inflammatory response to the ischemic process of the optic nerve head (Figure 1B). Serologic tests were positive for both immunoglobulin (Ig)M and IgG anti-VZV antibodies, confirming recent primary VZV infection. The diagnosis of ischemic vasculitis of the small retinal vessels associated with chickenpox was made. Since this process could either be caused by infection or an immunological response to VZV infection, and there is no consensus on the optimal treatment regimen for this VZV-associated vasculopathy, either treated with antiviral alone or combined with corticosteroid, we decided to treat the patient with antiviral agent according to the acute retinal necrosis treatment guideline published by the American Uveitis Society, ie, with intravenous Acyclovir $10 \mathrm{mg} / \mathrm{kg}$ every 8 hours for 2 weeks in conjunction with intravenous methylprednisolone $1 \mathrm{~g}$ daily for 3 days, then with oral prednisolone tapering over 1 month and oral Acyclovir $800 \mathrm{mg} 5$ times daily for 1 month. Despite the treatment, a pale optic disc and attenuated retinal artery resulted. His final best-corrected visual acuity was counting fingers at 1 foot at 6 months' follow-up.

\section{Conclusion}

To our knowledge, this is the first case of isolated ischemic retinal vasculitis associated with primary VZV infection that has been fully investigated. Fundus fluorescein angiography, electrophysiologic studies, and magnetic resonance imaging confirmed the diagnosis of an ischemic process of generalized retinal vasculitis involving the optic disc. It is uncertain whether this resulted from an immunologic response or the infectious process caused by VZV. Treatment with systemic steroids alone or combined with antiviral agents has been described in previous case reports of optic neuritis or vasculitis-associated $\mathrm{VZV} .^{4-7}$ The poor visual outcome in our patient can be explained by the generalized ischemic process of both the retina and optic disc. However, prompt treatment with antivirals and high-dose steroids should be administered in patients with VZV associated with ischemic retinal vasculitis to counter both inflammation and infarction.

\section{Disclosure}

The authors report no conflicts of interest in this work.

\section{References}

1. Yoshida M, Hayasaka S, Yamada T, et al. Ocular findings in Japanese patients with varicella-zoster virus infection. Ophthalmologica. 2005;219(5):272-275.

2. Mueller NH, Gilden DH, Cohrs RJ, Mahalingam R, Nagel MA. Varicella zoster virus infection: clinical features, molecular pathogenesis of disease, and latency. Neurol Clin. 2008;26(3):675-697, viii.

3. Culbertson WW, Brod RD, Flynn HW Jr, et al. Chickenpox-associated acute retinal necrosis syndrome. Ophthalmology. 1991;98(11): 1641-1645.

4. Salazar R, Russman AN, Nagel MA, et al. Varicella zoster virus ischemic optic neuropathy and subclinical temporal artery involvement. Arch Neurol. 2011;68(4):517-520.

5. Stergiou PK, Konstantinou IM, Karagianni TN, Kavaki D, Printza NG. Optic neuritis caused by varicella infection in an immunocompetent child. Pediatr Neurol. 2007;37(2):138-139.

6. MacKinnon JR, Lim Joon T, Elder JE. Chickenpox neuroretinitis in a 9 year old child. Br J Ophthalmol. 2002;86(4):475-476.

7. Tappeiner C, Aebi C, Garweg JG. Retinitis and optic neuritis in a child with chickenpox: case report and review of literature. Pediatr Infect Dis $J$. 2010;29(12):1150-1152.

8. Kuo YH, Yip Y, Chen SN. Retinal vasculitis associated with chickenpox. Am J Ophthalmol. 2001;132(4):584-585.
Clinical Ophthalmology

\section{Publish your work in this journal}

Clinical Ophthalmology is an international, peer-reviewed journal covering all subspecialties within ophthalmology. Key topics include: Optometry; Visual science; Pharmacology and drug therapy in eye diseases; Basic Sciences; Primary and Secondary eye care; Patient Safety and Quality of Care Improvements. This journal is indexed on

\section{Dovepress}

PubMed Central and CAS, and is the official journal of The Society of Clinical Ophthalmology (SCO). The manuscript management system is completely online and includes a very quick and fair peer-review system, which is all easy to use. Visit http://www.dovepress.com/ testimonials.php to read real quotes from published authors. 